\title{
Arsitektur dalam Penanganan Ketergantungan Narkotika dengan Pendekatan Biophilic
}

\author{
Kusmira Okvi Karenza dan Rullan Nirwansjah \\ Departemen Arsitektur, Fakultas Teknik Sipil dan Perencanaan, Institut Teknologi Sepuluh Nopember (ITS) \\ e-mail: rullan@arch.its.ac.id
}

\begin{abstract}
Abstrak-Penyebaran narkoba tiap tahun semakin meningkat dan telah merusak bebagai kalangan. Akan tetapi proses pengobatan yang dilakukan seringkali tidak memperhatikan faktor lingkungan dan kebutuhan manusia. Proses rehabilitasi pengguna narkoba memerlukan tempat serta lingkungan yang dapat mengurangi penggunaan narkoba secara bertahap hingga sepenuhnya terlepas. Arsitektur dari tempat rehabilitasi sejatinya melebur dalam proses rehabilitasi itu sendiri. Arsitektur digunakan sebagai media dalam rehabilitasi, sehingga implementasi arsitektur dapat menyentuh tidak hanya fisik namun juga psikis manusia yang menempatinya. Pendekatan biophilic mengaplikasikan desain yang memuat elemen alam untuk meningkatkan kualitas hidup, di dalamnya melibatkan kesehatan dan kesejahteraan fisiologis maupun psikologis manusia. Diharapkan konsep arsitektur ini dapat membantu proses rehabilitasi pengguna narkoba menjadi lebih efektif dan efisien.
\end{abstract}

Kata Kunci-Arsitektur, Biophilic, Rehabilitasi Narkoba.

\section{PENDAHULUAN}

$\mathrm{P}$ ENGGUNAAN narkoba dan obat-obatan terlarang saat ini marak terjadi di Indonesia, korban penyalahgunaan obatobat terlarang ini dapat dialami oleh siapa saja. Dalam kehidupan manusia fase remaja merupakan masa penting dimana manusia rentan akan badai dan tekanan. Mental individu tersebut sudah tidak lagi dipandang dan diperlakukan sebagai anak-anak, namun juga belum sepenuhnya mempraktikan pola perilaku pada usia dewasa

Kegagalan remaja dalam mengembangkan identitas pribadinya dapat disebabkan oleh masa kanak-kanak yang tidak memberikan basis memadai bagi proses identifikasi diri dan lingkungan sosial remaja yang tidak mendukung. Padahal kalangan pemuda menjadi catatan khusus, mengingat mereka merupakan sumber daya manusia berusia produktif yang sangat diandalkan sebagai penggerak dalam program pembangunan nasional.

Individu menggunakan narkoba sebagai wujud pemberontakan. Terdorong oleh hasrat untuk mengekspresikan diri sebagai individu mandiri. Sekelompok individu menggunakan narkoba sebagai bahasa isyarat bahwa mereka kini mampu melakukan hal yang mereka mau tanpa harus mendapatkan lampu hijau dari pihak lain. Tidak semua pengguna narkoba menjadi pecandu. Sebagian menggunakan narkoba sebagai bagian dari proses sosial mereka. Sebagian besar yang lain terjebak ke dalam jurang sebagai pecandu, bahkan pengedar narkoba.

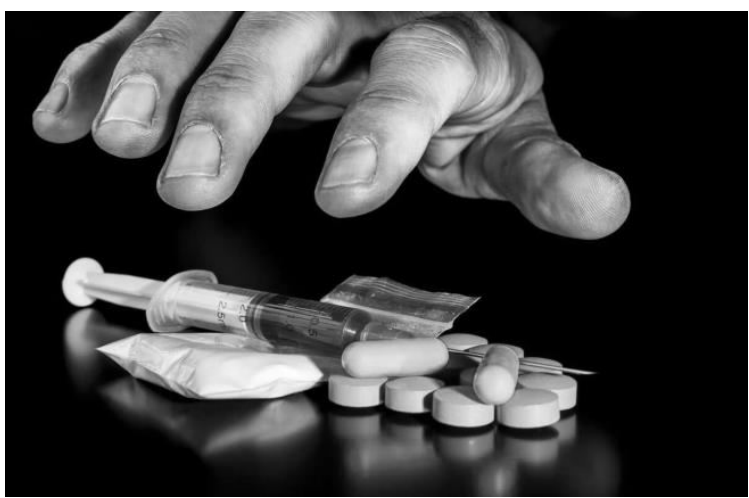

Gambar 1. Macam obat-obatan terlarang.

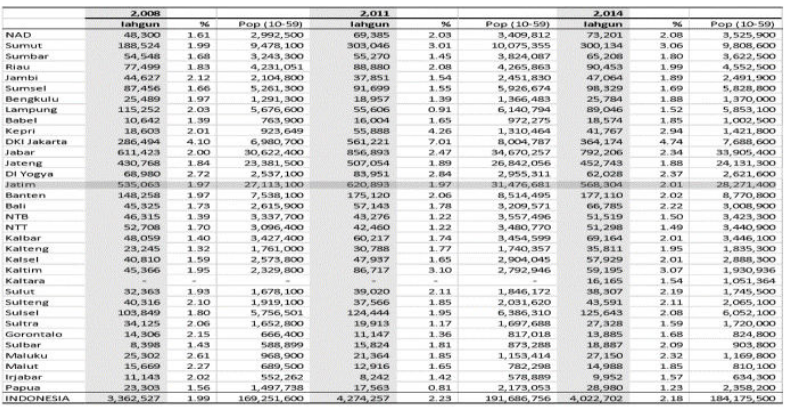

Gambar 2. Perkembangan penyalahgunaan narkoba tahun 2014.

(Sumber: Badan Nasional Narkotika 2014)

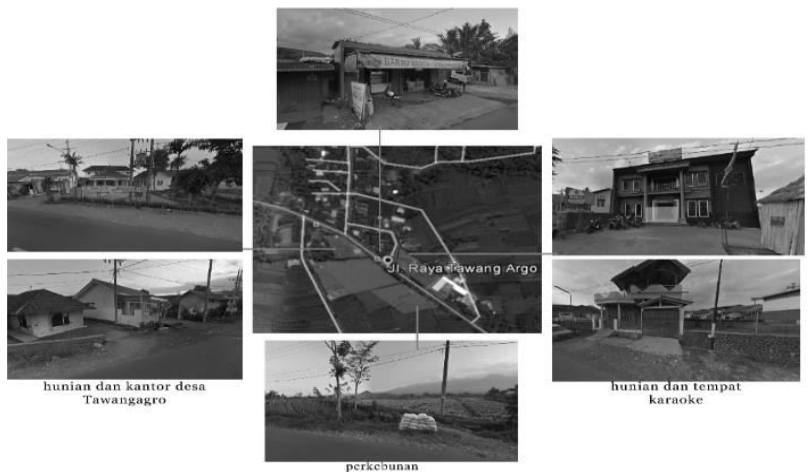

Gambar 3. Kondisi lingkungan lahan.

(Sumber: www.google.com)

Padahal dampak yang ditimbulkan dari penggunaan narkoba mengakibatkan ketergantungan fisik dan psikis, sehingga menimbulkan masalah kepribadian dan perubahan perilaku dalam kehidupan sosial. 


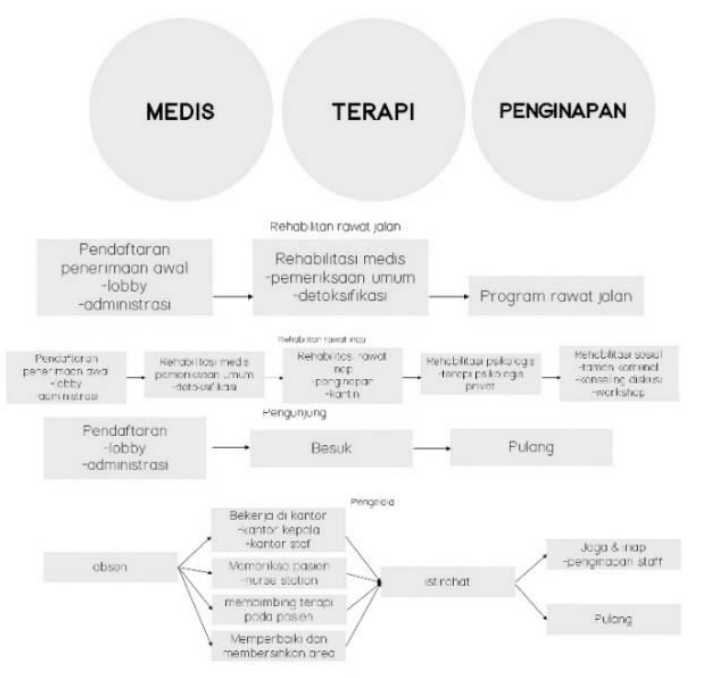

Gambar 4. Program desain.

(Sumber: Dokumen Pribadi)

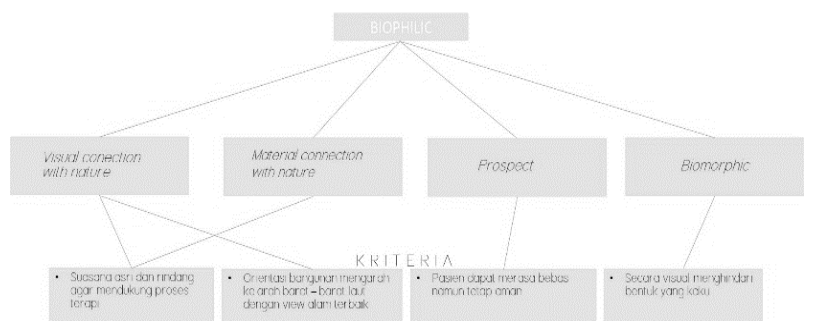

Gambar 5. Diagram konsep (Sumber: Dokumen Pribadi)
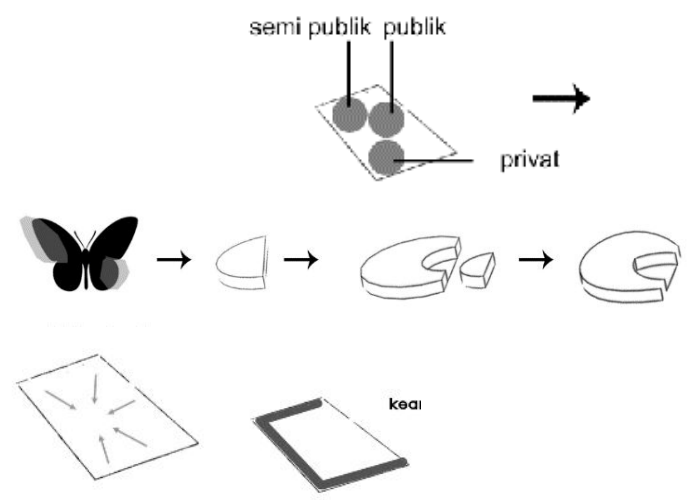

Gambar 6. Konsep

(Sumber: Dokumen Pribadi)

\section{B, Tujuan Desain}

Tujuan desain yang ingin dicapai pada proyek ini adalah arsitektur sebagai sebuah wadah sarana yang dapat membantu menyembuhkan fisik dan kondisi psikis korban menjadi lebih baik dengan memberikan suasana yang mendukung proses terapi dan menyiapkan kondisi mental pasien agar siap kembali ke masyarakat.

\section{Kriteria Desain}

1. Suasana asri dan rindang agar mendukung proes terapi

2. Orientasi bangunan mengarah ke arah barat-barat laut denan view alam terbaik

3. Secara visual menghindari bentuk yang kaku

4. Pasien dapat merasa bebas namun tetap aman
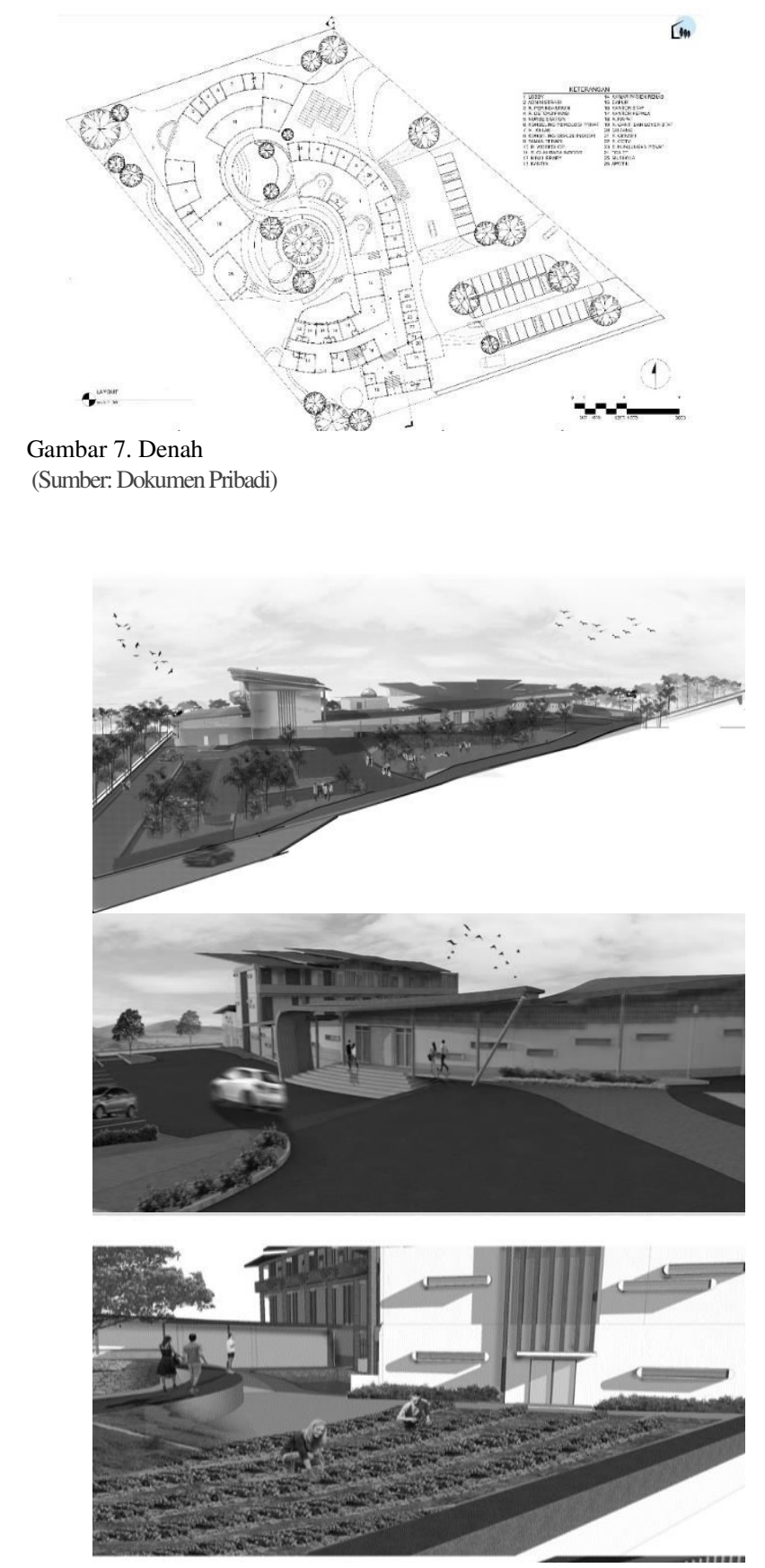

Gambar 8. Perspektif

(Sumber: Dokumen Pribadi)

\section{URAIAN PENELITIAN}

\section{A. Pendekatan}

Untuk menjawab permasalahan desain yang ada digunakan pendekatan Human Needs Maslow. Dan berdasarkan isu dan usulan objek, mengarah pada fasilitas atau objek rancang yang dapat memenuhi kebutuhan masing-masing pasien yang mempunya gejala yang berbeda. adi objek yang dihadirkan adalah sebuah tempat rehabilitasi dengan memenuhi kebutuhan pasien dan diharapkan pasien tidak merasa takut, kuat mental, tenang sehingga dapat mendukung proses penyembuhan dan terapi.

\section{B. Metode}

Untuk menjawab bagaimana menghadikan lingkungan yang 
mempengaruhi penyembuhan pecandu narkoba agar meminimalisir kembalinya mantan pecandu menggunakan narkoba, maka dipilihlah metode biophilic. konsep ini mengaplikasikan desainnya dengan memuat elemen alam untuk meningkatkan kualitas hidup yang melibatkan kesehatan dan kesejahteraan fisiologis maupun psikologis manusia. Pada biophilic terdapat 14 pola namun berdasarkan fungsi dan isu dipilih beberapa pola yang dipakai nantinya di dalam bangunan.

\section{HASIL DAN EKSPLORASI}

Eksplorasi awal yang dilakukan berkaitan menentukan kebutuhan ruang dari aktivitas penanganan ketergantungan narkoba. Setelah ditentukan kebutuhan ruang maka menentukan tata letak dan zonasi dan memenuhi kriteria desain yang telah dibuat.

Tatanan masa bangunan diatur berdasarkan pendekatan biofilia dengan konsep Nature of work and collaboration dengan memperhatikan orientasi matahari dan view ke alam. Area semi publik diletakan disisi utara karena kontur yang lebih tinggi dibanding area lain. Publik diletakkan didepan karena fungsinya sebagai area rawat jalan.

Konsep Bentuk yang dipakai adalah Biomorphic yang merupakan salah satu pola yang ada di Biofilia. Biomorphic merupakan pengambilan bentuk dari alam, pada bangunan ini menggunaan elemen metamorfosis kupu-kupu. Karena pemaknaan dari proses metamorfosis kupu-kupu yang dianggap sama dengan proses penyembuhan pecandu narkoba. Dimana metamorfosis kupu-kupu dari ulat yang cenderung dibenci.

Konsep Ruang kamar penginapan dibedakan tiap golongan tingkat ketergantungan berdasarkan zat yang dicandu serta gejala-gejalanya.

Sebagai respon dari kriteria desain keamanan maka ruang luar dibuat terpusat, serta batas luar lahan dibuat dengan batas alami yaitu dengan kontur lahan dan vegetasi.
Sistem struktur yang digunakan adalah rigid frame denga struktur atap trus. Struktur dipakai agar mempertahankan bentuk atap dan kebutuhan ruang didalamnya.

\section{KESIMPULAN}

Fasilitas rehabilitasi korban ketergantungan narkoba ini dirancang berdasarkan isu mengenai penanganan psikologis yang masih kurang maksimal karena kurangnya fasilitas dan suasana lingkungan yang masih belum mendukung proses terapi. Fasilitas dan elemen-elemen arsitektur yang dihadirkan pada objek rancang ini, diharapkan dapat membantu proses terapi dan dapat mempengaruhi psikologis dan sosial pasien agar pasien dapat kembali serta diterima oleh masyarakat.

\section{DAFTAR PUSTAKA}

[1] Inragiri, Reza. Psikologi Kaum Muda Pengguna Narkoba.

[2] Duerk, Donna P. (1993), Architectural Programming- information management for design

[3] White, Edward T. (2004), Site Analysis Diagramming Information For Architectural Design

[4] Neufert, Ernst. (1991), Data Arsitek Edisi 3, Erlangga, Jakarta

[5] Adler, David. (1999), Metric Handbook - Planning and Design Data, Architectural Press, UK

[6] De Chiara, Joseph (1983). Time saver standart for building types. McGraw hill; Singapore

[7] Browning, William (2014),14 Patterns Biophilic Design . Terrapin Bright Green; Ne York

[8] Anonim, 2008. Jurnal Online: "Dampak Narkoba”.[online]. https://jauhinarkoba.com/dampak-narkoba/. Diakses tanggal 11 Oktober 2016

[9] Johny, 2011. Jurnal Online: "Faktor Pemicu Penggunaan Narkoba".[online]. http://kliniknarkoba.blogspot.co.id/2011/05/faktorpemicu-penggunaan-narkoba.html. Diakses tanggal 12 Oktober 2016

[10] BNN, 2014. Jurnal Online: "Laporan Akhir Survei Nasional Perkembangan Penyalahguna Narkoba Tahun Anggaran 2014“. [online]. http://www.bnn.go.id/portal/_uploads/post/2015/03/11/Laporan_BNN_2 014_Upload_Humas_FIX.pdf. Diakses tanggal 27 Oktober 2016 